\title{
Dedication
}

\section{Stephen KM Lau: Hong Kong Privacy Commissioner, Chairman EDS Hong Kong, Internet Governance Forum}

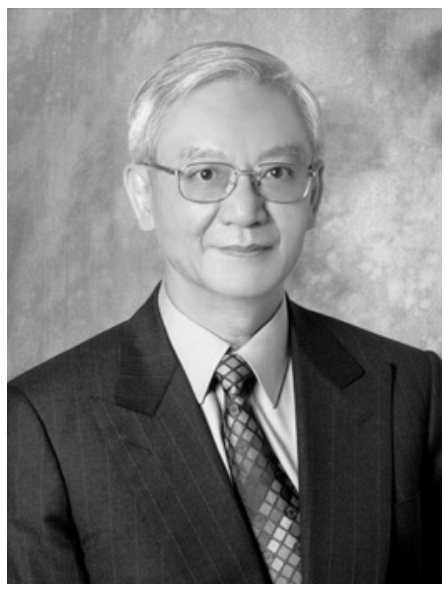

Stephen Lau has more than 30 years experience in information technology and financial services related industries in both the government and private sectors. As the first Privacy Commissioner for Hong Kong he introduced a number of measures to ensure greater protection of personal data relating to Hong Kong citizens collected by the government and continues to work with leaders in data protection around the world. He served as Departmental Head of the Hong Kong Government Data Processing Agency, Head of Operations and Technology for Citicorp Asia-Pacific and is currently Chairman of EDS Hong Kong.
Due to his long experience in information policy and privacy protection issues, in 2008 he was appointed a member of the UN Multistakeholder Advisory Group of the Internet Governance Forum. The 50 advisors recently assembled to consider Internet issues including access, multilingualism, cyber-security, transition from IPv4 to IPv6, and emerging issues.

Stephen is active in Community Affairs, holding chairmanships in a number of advisory committees of the Government and Universities. An Adjunct Professor at the City University of Hong Kong, he was Vice President for Professional Development of the Hong Kong Computer Society. He currently the chairman of the Asia Pacific ICT Alliance (APICTA), an umbrella organization of 16 Asia Pacific economies which hosts the annual Asia Pacific ICT Awards to recognize the best-of-the-best ICT products and applications to showcase product excellence, bridge the digital divide, and enhance business and professional relationships across the region.

He holds a bachelor's degree from the University of Manchester, a Masters in Computer Science from London University and completed a senior executive program at the Harvard Business School.

Russell Pipe, Editor 